\title{
Breast cancer prevention in the developing world
}

\author{
Jack Cuzick*
}

Breast cancer is already by far the commonest cancer in women worldwide, with an estimated 1.4 million cases in 2008 [1]. The rates have been increasing steadily and there is every indication that they will continue to do so over the next few decades. The greatest increases are in the developing world, where rates have traditionally been low, but with changing lifestyle they look destined to approach rates seen in western countries. In addition to this, the lifespan of women in the developing world is also increasing and so far more women are reaching an age where breast cancer rates are high. Thus, the increase in breast cancer incidence, to a large extent, reflects the major successes achieved in the developing world in combating infectious diseases and maternal deaths from childbirth.

There is little that can be done to deal with this success in preventing other diseases except to redirect more treatment and palliative resources to the problem, and to try to find affordable and acceptable methods of providing screening programmes. However, there is some scope to try to hold in check the results of lifestyle changes, which are leading to the increase in age-specific breast cancer rates. Thus, three broad approaches are possible within the screening and prevention arena: lifestyle changes to reduce or control increases in incidence rates; preventive therapy in high risk women; and breast screening.

\section{Lifestyle}

Much of the difference in breast cancer incidence between developed and developing countries can be explained by lifestyle differences. In particular, it has been estimated that differences in childbirth patterns and breast feeding can explain about a two-fold lower agespecific incidence in the developing world, where a woman starts childbearing at a young age, has a large family and breast feeds each child for 1 to 2 years. Certainly there are enough other problems with large

*Correspondence: j.cuzick@qmul.ac.uk

Cancer Research UK Centre for Epidemiology, Mathematics and Statistics, Wolfson Institute of Preventive Medicine, Queen Mary University of London, Charterhouse Square, London, EC1M 6BQ, UK families to not recommend the maintenance of this practice, but continuing a high level of breast feeding offers one possible hope for containing the increase in breast cancer. It has been estimated from a large overview [2] that the relative risk of breast cancer is reduced by $4.3 \%$ for every cumulative year of breast feeding, so 2 to 3 years of lifetime breast feeding could reduce incidence by $10 \%$ or so. Another concern, which is important worldwide, are increases in obesity and reductions in physical activity. Much of the developing world has moved to a starchy, grain-based diet, which has led to several health issues, notably a skyrocketing of type 2 diabetes. However, its impact on post-menopausal breast cancer has yet to be fully seen. Estimates suggest postmenopausal breast cancer incidence increases by about $1 \%$ per kilogram of adult weight [3], so that a $20 \mathrm{~kg}$ or greater difference would have an important impact at a population level. Weight gain in middle age appears to be important [4], so programmes aimed at both childhood and adult weight control would be valuable.

Physical exercise is also a protective factor, with even modest amounts of moderate to vigorous activity ( 2 to 3 hours per week) having a 20 to $40 \%$ impact on incidence [5]. Control of alcohol consumption is also an issue, with an estimated relative risk increase of $7 \%$ for each drink consumed on a daily basis [6]. This is also a worldwide issue.

\section{Preventive therapy}

Tamoxifen and raloxifene have both been shown to reduce the incidence of breast cancer by 30 to $40 \%$ and are licensed for prevention in some countries. However, they have significant toxicity and use needs to be focused on high risk subgroups. Identification of such subgroups is potentially difficult in developing countries, and this strategy is best reserved for the developed world until procedures for identifying high risk women are more completely developed.

\section{Screening}

When practiced by well trained personnel, mammographic screening is effective at reducing mortality by 30 to $40 \%$, albeit at the expense of some overdiagnosis and treatment. However, the costs and infrastructure required make this infeasible for many parts of the 
developing world (especially Africa), and only moderately resourced countries - for example, those in Eastern Europe - can seriously consider this now. At the other extreme, breast self-examination has proved to be ineffective $[7,8]$ and should not be recommended. A promising approach being explored in a large trial in Mumbai $(\mathrm{n}=150,000)$ is clinical breast examination by trained doctors and nurses [9]. This would appear feasible in low resource settings and the results of this trial are eagerly awaited.

\section{Conclusion}

Large increases in the number of breast cancer patients are certain to occur in the next few decades, partly as a result of the success in eradicating infectious diseases and maternal deaths, but also due to the 'westernisation' of lifestyle with its attendant increase in an individual risk, especially in the post-menopausal period. Control of certain lifestyle factors, notably maintaining breast feeding, avoiding obesity, alcohol consumption, and maintaining a high level of physical activity, may help to control this last factor.

Mammographic screening may be useful in some areas where adequate resources exist, but is currently not viable for much of the developing world, and the results of the trial on clinical breast examination are awaited as a further possible approach. Providing adequate treatment facilities and palliation should be the current priorities.

\section{Competing interests}

The author's institute receives support from AstraZeneca to conduct a prevention trial with anastrozole and the author is on their advisory board.

\section{Acknowledgements}

This article has been published as part of Breast Cancer Research Volume 12 Supplement 4, 2010: Controversies in Breast Cancer 2010. The full contents of the supplement are available online at http://breast-cancer-research.com/ supplements/12/S4

Published: 20 December 2010
References

1. Ferlay J, Shin HR, Bray F, Forman D, Mathers C, Parkin DM: Estimates of worldwide burden of cancer in 2008: GLOBOCAN 2008. Int J Cancer 2010, [Epub ahead of print].

2. Collaborative Group on Hormonal Factors and Breast Cancer: Breast cancer and breastfeeding: collaborative reanalysis of individual data from 47 epidemiological studies in 30 countries, including 50302 women with breast cancer and 96973 women without the disease. Lancet 2002, 360:187-195.

3. Renehan AG, Tyson M, Egger M, Heller RF, Zwahlen M: Body-mass index and incidence of cancer: a systematic review and meta-analysis of prospective observational studies. Lancet 2008, 371:569-578.

4. Harvie M, Howell A, Vierkant RA, Kumar N, Cerhan JR, Kelemen LE, Folsom AR, Sellers TA: Association of gain and loss of weight before and after menopause with risk of postmenopausal breast cancer in the lowa women's health study. Cancer Epidemiol Biomarkers Prev 2005, 14:656-661.

5. Bernstein L, Patel AV, Ursin G, Sullivan-Halley J, Press MF, Deapen D, Berlin JA, Daling JR, McDonald JA, Norman SA, Malone KE, Strom BL, Liff J, Folger SG, Simon MS, Burkman RT, Marchbanks PA, Weiss LK, Spirtas R: Lifetime recreational exercise activity and breast cancer risk among black women and white women. J Natl Cancer Inst 2005, 97:1671-1679.

6. Hamajima N, Hirose K, Tajima K, Rohan T, Calle EE, Heath CW Jr, Coates RJ, Liff JM, Talamini R, Chantarakul N, Koetsawang S, Rachawat D, Morabia A, Schuman L, Stewart W, Szklo M, Bain C, Schofield F, Siskind V, Band P, Coldman AJ, Gallagher RP, Hislop TG, Yang P, Kolonel LM, Nomura AM, Hu J, Johnson KC, Mao Y, De Sanjosé S, et al.: Alcohol, tobacco and breast cancer - collaborative reanalysis of individual data from 53 epidemiological studies, including 58,515 women with breast cancer and 95,067 women without the disease. Br J Cancer 2002, 87:1234-1245.

7. Semiglazov VF, Sagaidak VN, Moiseyenko VM, Mikhailov EA: Study of the role of breast self-examination in the reduction of mortality from breast cancer. The Russian Federation/World Health Organization Study. Eur J Cancer 1993, 29A:2039-2046.

8. Thomas DB, Gao DL, Ray RM, Wang WW, Allison CJ, Chen FL, Porter P, Hu YW, Zhao GL, Pan LD, Li W, Wu C, Coriaty Z, Evans I, Lin MG, Stalsberg H, Self SG: Randomized trial of breast self-examination in Shanghai: final results. J Natl Cancer Inst 2002, 94:1445-1457.

9. Mittra I, Mishra GA, Singh S, Aranke S, Notani P, Badwe R, Miller AB, Daniel EE, Gupta S, Uplap P, Thakur MH, Ramani S, Kerkar R, Ganesh B, Shastri SS: A cluster randomized, controlled trial of breast and cervix cancer screening in Mumbai, India: methodology and interim results after three rounds of screening. Int J Cancer 2010, 126:976-984.

doi:10.1186/bcr2738

Cite this article as: Cuzick J: Breast cancer prevention in the developing world. Breast Cancer Research 2010, 12(Suppl 4):S9. 